\title{
Anti-myelin-associated glycoprotein peripheral neuropathy as the only presentation of low grade lymphoma: a case report Costantine Albany
}

Address: Department of Medicine, St. Luke's - Roosevelt Hospital, Columbia University College of Physicians and Surgeons, 1000 Tenth Ave New York, NY 10019, USA

Email: ca2341@columbia.edu

Received: 3 March 2009 Accepted: 18 July 2009 Published: 27 July 2009

Cases Journal 2009, 2:6370 doi: 10.4076/1757-1626-2-6370

This article is available from: http://casesjournal.com/casesjournal/article/view/6370

(C) 2009 Albany; licensee Cases Network Ltd.

This is an Open Access article distributed under the terms of the Creative Commons Attribution License (http://creativecommons.org/licenses/by/3.0), which permits unrestricted use, distribution, and reproduction in any medium, provided the original work is properly cited.

\begin{abstract}
Peripheral nervous system involvement has been reported in systemic B or T cell lymphoma and may result from many mechanisms. We present a case of 59-year-old Caucasian man presented with a three years history of progressively worsening peripheral neuropathy with no obvious reason. An extensive workup revealed anti-myelin-associated glycoprotein neuropathy as the only presenting feature of low grade B cell Lymphoma.
\end{abstract}

\section{Introduction}

Peripheral nervous system involvement has been reported in systemic B or T cell lymphoma and may result from many mechanisms. Intraneural localization of lymphoma could result in meningo-radiculopathy or mononeuropathies, or manifest as a sensory-motor polyneuropathy sometimes mimicking chronic inflammatory demyelinating polyneuropathy. We report here the case of a patient with a previously unknown NHL presenting with a progressive symmetric polyneuropathy found to have Anti-Myelin-Associated Glycoprotein (Anti MAG) peripheral neuropathy. The extensive work up revealed the diagnosis of low grade B-cell lymphoma.

\section{Case presentation}

A 59-year-old Caucasian man presented with a three years history of progressively increasing pain, parasthesias and numbness of lower extremities bilaterally. The disease progressed to painful disabling weakness in lower extremities and later it involved his arms. There were no sphincter disturbances or back pain. The patient reports $25 \mathrm{lbs}$ weight loss during this period. Otherwise his past medical history was unremarkable. He denied any history of smoking or alcohol intake and there was no significant family history.

On physical examination, the vital signs were a blood pressure (BP) of 110/80 mmHg, heart rate (HR) 78/min, respiratory rate (RR) 20/min and body temperature (T) $36.2^{\circ} \mathrm{C}$. The patient appeared alert and oriented. There were no lymph nodes palpable. Physical examination of the chest, abdomen, back and extremities were unremarkable. Neurological exam revealed evidence of bilateral lower extremity weakness with motor power $4 / 5$ in distal muscular group, hypoactive reflexes in four extremities, along with hypoesthesia and decreased deep sensation.

A work up for peripheral neuropathy revealed normal TSH, Vitamin B12 and CPK. Monospot test, VDRL, HIV antibody, P- and C-ANCA, ANA, anti double-stranded 
Table I. Laboratory data

\begin{tabular}{llll}
\hline TSH & $\mathrm{I} .3 \mathrm{uU} / \mathrm{ml}$ & ANA & $<1 / 40$ \\
CPK & $34 \mathrm{mg} / \mathrm{dl}$ & ANCA & Negative \\
LDH & $132 \mathrm{mg} / \mathrm{dl}$ & HIV & Negative \\
Vit BI2 & $376 \mathrm{pg} / \mathrm{ml}$ & VDRL & Negative \\
\hline
\end{tabular}

DNA were all negative (Table 1). Electromyography (EMG) of the lower extremities showed axonal neuropathy. MRI of the spine ruled out cord lesion. CSF examinations repeatedly showed increased protein levels $(80-91 \mathrm{mg} / \mathrm{dl})$ with slightly increased white cells $\left(<10 \mathrm{~mm}^{3}\right)$ but no malignant cell identified (Table 2). Serum protein electrophoresis (SPEP) with immunofixation revealed IgM Kappa monoclonal spike. Quantative immunoglobulin analysis revealed an elevated IgM level at $313 \mathrm{mg} / \mathrm{dL}$ (the upper limit of normal is 230). Anti MAG Ab were over a million. Bone marrow biopsy and aspiration disclosed low grade CD20 positive B-cell lymphoma (Figure 1 and 2). Following the diagnosis of lymphoma patient underwent therapy with Rituximab with very good response. His neuropathy symptoms improved and his follow up Anti MAG Ab level markedly decreased (Table 3).

\section{Discussion}

There are many possible causes of peripheral neuropathy. Lymphoma can affect the peripheral nervous system in $5 \%$ of patients [1]. When it does, the diagnosis can be challenging since many patients present without established diagnosis of lymphoma. In lymphoma patients most peripheral nerve complications are due to nonHodgkin's lymphoma (NHL). NHL can cause neuropathy by directly compressing or infiltrating nerves or by remote effects. Neuropathies could present as mononeuropathy or polyneuropathy, and may resemble an asymmetric mononeuropathy multiplex or a generalized disorder such as chronic inflammatory demyelinating polyradiculoneuropathy. Hodgkin's lymphoma (HL), by contrast, rarely infiltrates nerves. More often, HL causes immunological disorders of the peripheral nervous system such as Guillain-Barre syndrome.

Approximately $10 \%$ of patients with peripheral neuropathy of otherwise unknown etiology have an associated monoclonal gammopathy. The hematological condition mainly associated with this entity is MGUS, but other malignancies may also occur [2,3]. Disorders such as multiple myeloma, AL amyloidosis, Waldenström's macroglobulinemia, osteosclerotic myeloma, and lymphoma have been reported [4]. Features which suggest malignancies include weight loss, rapid progression of the

Table 2. CSF finding

\begin{tabular}{llll}
\hline WBC & I cells $/ \mathrm{mm}^{3}$ & Glucose & $58 \mathrm{mg} / \mathrm{dl}$ \\
RBC & I cells $/ \mathrm{mm}^{3}$ & Protein & $94 \mathrm{mg} / \mathrm{dl}$ \\
\hline
\end{tabular}

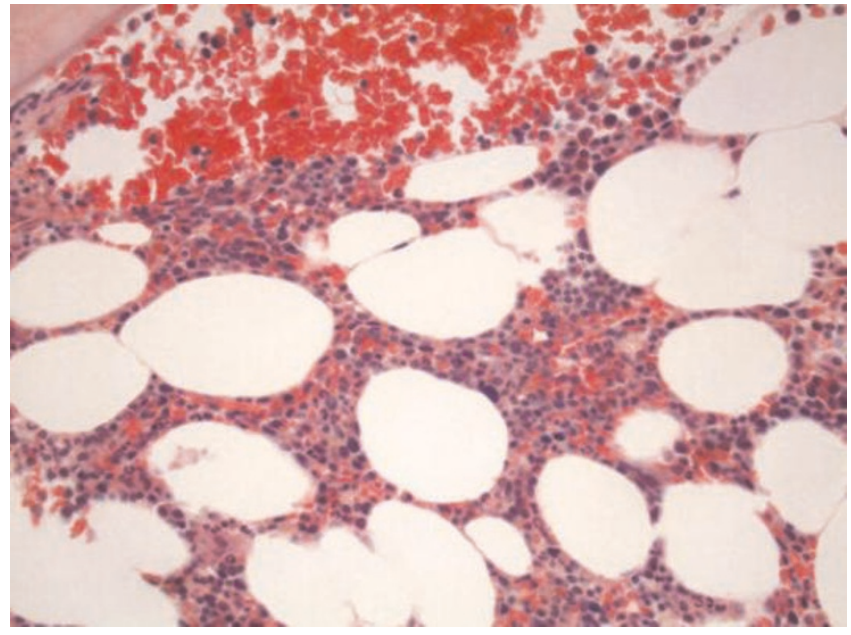

Figure I. Low grade B cell Lymphoma on bone marrow biopsy (Hematoxylin and Eosin stain).

neuropathy, higher levels of paraprotein $(>1 \mathrm{~g} / \mathrm{l})$, elevated levels of beta-2-microglobulin and light chain proteinuria.

The anti-myelin-associated glycoprotein (MAG) neuropathy is a very rare antibody-mediated demyelinating neuropathy. The clinical picture is characterized by a distal and symmetric, mostly sensory neuropathy. Monoclonal immunoglobulin $\mathrm{M}$ anti-MAG antibodies are uniquely found in this condition and are believed to be pathogenic. Biopsy of nerve tissue from anti-MAG patients, demonstrates immunoglobulin $\mathrm{M}$ deposits at the site of MAG localization, demyelination and axonal degeneration. MAG is a Schwann cell-based glycoprotein and has been

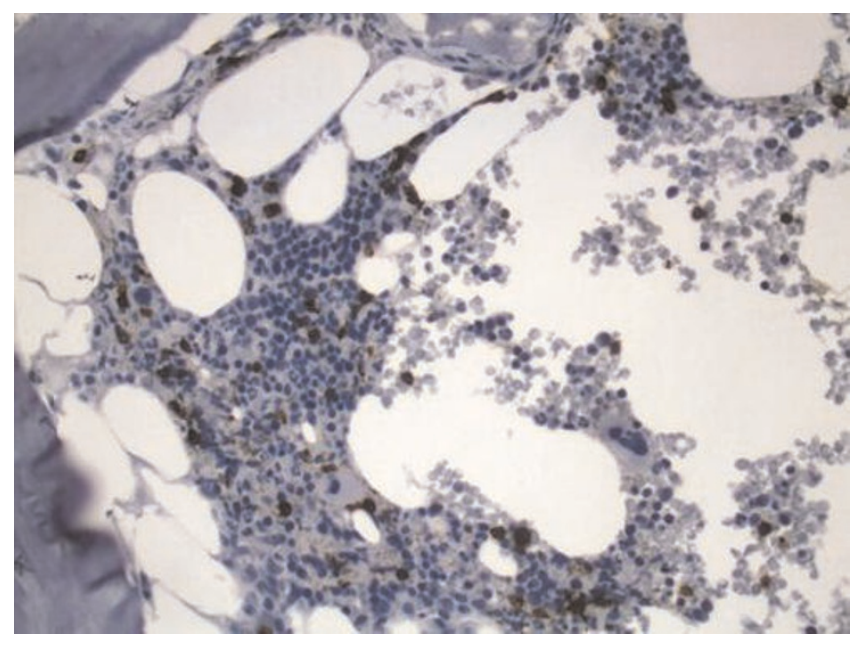

Figure 2. Low grade B cell Lymphoma CD20 positive on bone marrow biopsy. 
Table 3. Anti MAG Ab follow up

\begin{tabular}{lll}
\hline T0 & T6 & TI2 \\
$\mathrm{I} / \mathrm{I}, 102,400$ & $\mathrm{I} / 200,000$ & $\mathrm{I} / 25,600$ \\
\hline
\end{tabular}

T0 upon diagnosis, T6 and TI2 are after 6, 12 months follow up.

implicated as a mediator of an outside-in signaling cascade influencing the cytoskeletal integrity of axons.

Therapy in patients with anti-MAG neuropathy is directed at reducing the antibody concentration, and depleting the monoclonal B cells. Therapeutic intervention depends on the specific clinical syndrome but is generally directed at removing the autoantibodies, reducing the number of monoclonal B cells, and interfering with the effector mechanisms [5]. The recent availability of rituximab, a monoclonal antibody suppressing B-cell clones, which is not myelosuppressive and does not cause secondary malignancies, allows for early targeted intervention [6,7]. Many clinical trials, [8] have shown that in patients with IgM autoantibody associated peripheral neuropathies; rituximab treatment is followed by reduced serum concentrations of IgM, and by improvement in clinical picture [9].

In our patient, a sensorimotor demyelinating neuropathy was associated with antibodies directed against the Myelin-Associated Glycoprotein. Therefore, we present a rare case of a patient with paraproteinemic polyneuropathy who has IgM autoantibodies against MyelinAssociated Glycoprotein with underlying low grade B-cell lymphoma. The IgM type of these autoantibodies suggests that they represent all or part of the paraprotein produced by lymphoma cells. The patient responded well to rituximab treatment with significant improvement of his numbness and moderate improvement of his lower extremities weakness in three months.

\section{Abbreviations}

MAG, anti-myelin-associated glycoprotein; NHL, nonHodgkin's lymphoma; HL, Hodgkin's lymphoma; SPEP, Serum protein electrophoresis; ANA, Antinuclear Antibodies; ANCA, Anti-Neutrophil Cytoplasmic Antibodies; TSH, Thyroid Stimulating Hormone.

\section{Consent}

Written informed consent was obtained from the patient for publication of this case report and accompanying images. A copy of this written consent is available for review by the Editor-in-chief of this journal.

\section{Competing interests}

The author declares that they have no competing interests.

\section{References}

I. Hughes RA, Britton T, Richards M: Effects of lymphoma on the peripheral nervous system. J R Soc Med 1994, 87:526-530.
2. Marfia GA, Pachatz C, Terracciano C, Leone G, Bernardini S, Bernardi G, Massa R: Subacute demyelinating polyneuropathy in B-cell lymphoma with IgM antibodies against glycolipid GDIb. Neurol Sci 2005, 26:355-357.

3. Maillot F, Gelot A, Diot E, Larmande P, Guilmot JL: IgM anti-MAG neuropathy with involvement of the cranial nerves disclosing B-cell lymphoma. Ann Med Interne (Paris) 1996, 147:373-374 [French].

4. Bosch EP, Smith BE: Peripheral neuropathies associated with monoclonal proteins. Med Clin North Am 1993, 77:I25-I39.

5. Latov N: Pathogenesis and therapy of neuropathies associated with monoclonal gammopathies. Ann Neurol 1995, 37:S32-42.

6. Steck AJ, Stalder AK, Renaud S: Anti-myelin-associated glycoprotein neuropathy. Curr Opin Neurol 2006, 19:458-463.

7. Renaud S, Fuhr P, Gregor M, Schweikert K, Lorenz D, Daniels C, Deuschl G, Gratwohl A, Steck AJ: High-dose rituximab and antiMAG-associated polyneuropathy. Neurology 2006, 66:742-744.

8. Levine TD, Pestronk A: IgM antibody-related polyneuropathies: B-cell depletion chemotherapy using Rituximab. Neurology 1999, 52:1701-1704.

9. Pestronk A, Florence J, Miller T, Choksi R, Al-Lozi MT, Levine TD: Treatment of IgM antibody associated polyneuropathies using rituximab. J Neurol Neurosurg Psychiatry 2003, 74:485-489.

\section{Do you have a case to share?}

Submit your case report today

- Rapid peer review

- Fast publication

- PubMed indexing

- Inclusion in Cases Database

\section{Any patient, any case, can teach us something}

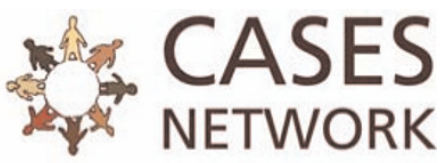

www.casesnetwork.com 